\title{
Consumption of Products from Heritage and Host Cultures: The Role of
}

Acculturation Attitudes and Behaviors

Dr. Hatice Kizgin, Lecturer**

Swansea University, School of Management

Bay Campus, Fabian Way, Swansea SA1 8EN

Phone: +44 (0)1792 604628

Email: Hatice.kizgin@swansea.ac.uk

Dr. Ahmad Jamal, Senior Lecturer

Cardiff University, Cardiff Business School

R36, Aberconway Building, Colum Road, Cathays, Cardiff, CF10 3EU

Phone: +44 (0)292087 6838

Email: jamala@cardiff.ac.uk

Prof. Michel Laroche, Royal Bank Distinguished Professor of Marketing John Molson School of Business Concordia University

John Molson Building, (Montreal, Quebec), Canada

Phone: +1 (514) 8482424

Email: michel.laroche@concordia.ca

**Corresponding Author 


\section{ABSTRACT}

Prior research ignores the specific role of acculturation attitudes in predicting acculturation behaviors and consumption choices across public and private life domains. The study uses self-administered questionnaires to collect data from 530 Turkish-Dutch respondents. The findings underscore the overall significance of investigating domainspecific (public vs. private) acculturation attitudes and subsequent acculturation behaviors. Enculturation (acculturation) behaviors function as a mediator variable in the relationship between acculturation attitudes and consumption of food and entertainment products from the heritage (host) culture. The study is the first of its kind to investigate the simultaneous effects of acculturation attitudes and acculturation behaviors on the choice to consume food and entertainment products from the heritage and host cultures. The study discusses implications and future research directions.

Keywords: Acculturation attitudes, Ethnic consumers, Bi-dimensional acculturation, Heritage and mainstream culture's food and entertainment products. 


\section{Introduction}

International migration levels are rising in the US (Jamal, Peñaloza and Laroche, 2015) and in Europe (Eurostat, 2015) and large ethnic-minority subcultures exist across the Western world (Jamal, 2003). The issues of cultural difference, interaction and change are at the heart of ethnic marketing research and practice (Jamal et al., 2015).

Consumer research (e.g., Wallendorf and Reilly, 1983) uses the assimilation or melting pot model (Gordon, 1964), which assumes that each ethnic minority group will blend into the host society, to determine whether immigrants' consumption patterns reflect the immigrants' culture of origin or the culture of residence. However, empirical studies show that the assimilation process is more than a linear progression from one culture to another (e.g., Laroche, Kim, Hui and Joy, 1996) and that assimilation is only a small part of the total acculturation phenomenon (Gentry, Jun and Tansuhaj, 1995), which refers to the notion of culture change that takes place as a result of contact with culturally dissimilar people and environments (Laroche and Jamal, 2015).

Consumer research implicitly acknowledges that immigrant consumers engage not only in acculturation but also in enculturation, which is the process of learning one's own culture (Schwartz, Unger, Zamboanga and Szapocznik, 2010). Cleveland and colleagues (2009), for example, report that immigrants "reside in a two-culture worldover time acquiring characteristics of the dominant culture, yet maintaining strong ties to their culture of origin" (p. 208). However, and despite the potential for navigating in between two worlds, the authors do not find any research that simultaneously investigates the effects of acculturation and enculturation on consumption choices. The authors address this research gap by simultaneously investigating the effects of acculturation and enculturation on immigrant consumers' consumption choices.

Moreover, the mechanisms involving enculturation and acculturation do not operate in a social vacuum but occur in the context of intra-group relationships 
(Horenczyk, 1997; Jamal and Chapman, 2000). Jamal (2003) reports that the extent to which immigrant consumers navigate in between two cultural worlds depends on the attitudes they hold toward heritage and host cultures. Josiassen (2011) shows that the immigrant consumers' perception of rejection and devaluation by the host society, along with strong identification with religious and ethnic groups, can trigger disidentification with host consumer culture. However, consumer research literature remains silent on the explicit role of acculturation attitudes towards host and heritage cultures in explaining acculturation behaviors and consumption patterns.

Moreover, prior research's treatment of acculturation attitudes remains problematic. For example, the widely cited work by Berry and colleagues (Berry, Kim, Power, Young and Bujaki, 1989; Berry, 2005) considers acculturation attitudes as "an individual's preference about how to acculturate" (p. 704). Others see acculturation attitudes as referring to preferences given to the cultures involved in the process (ArendsTóth and van de Vijver, 2006). However, prior research does not elaborate, in conceptual terms, how and on what basis acculturation attitudes are formed and why they can actually shape behavior.

Drawing from the Fishbein (1967) model in measuring attitude, this study considers consumer attitude as a function of the presence or absence and evaluation of belief and/or attributes (Schiffman and Kanuk, 2007). This helps in identifying and discussing the importance and desirability of specific salient beliefs involving host and/or heritage cultures. Acculturation attitudes are learned predispositions which can motivate consumers to act. While prior acculturation literature argues for a distinction between acculturation attitudes and acculturation behaviors (Arends-Tóth and van de Vijver, 2006; Berry, 1997), it generally remains silent in explaining the acculturation attitudebehavior link. This research contributes by investigating simultaneously the causal link 
from acculturation attitude to acculturation behavior.

The social psychology literature (e.g., Quarasse and van de Vijver, 2004) acknowledges the impact of public and private life domains on acculturation/enculturation including psychological and sociocultural adaptations. The private-life domain involves personal spheres like child-rearing practices, marital preferences, and family interactions, whereas the public domain involves social life (education life and professional life). However, prior consumer research only implicitly acknowledges the distinction between public and private domains by, for example, using language-based items to measure acculturation, so we do not know the extent to which immigrant consumers' preference for heritage (host) cultural maintenance (adaptation) across private- and public-life domains can impact their consumption patterns.

This shortcoming is addressed by investigating variations in attitudes about the heritage and host cultures, acculturation/enculturation preferences and consumption choices across both private and public life domains. In doing so, this work becomes part of a stream of research that argues in favor of capturing variations in immigrant consumers' preferences for adaptation and cultural maintenance across the private- and public-life domains (e.g., Arends-Tóth and van de Vijver, 2004). Unlike prior research, attitudinal predispositions toward maintaining cultural traditions in marriage and child rearing are treated as part of the private domain. Such attitudinal predispositions are seen as antecedents of subsequent preferences for acculturation or enculturation and, ultimately, for the choice to consume heritage or host culture products/services in the private- and public-life domains.

Finally, there is a sizeable Turkish diaspora to European countries, such as the Netherlands, where Turkish-Dutch people are the most visible minority-ethnic group (Arends-Tóth and van de Vijver, 2007). Scholarly work like that of Josiassen (2011), 
demonstrates that second-generation Turkish immigrants in the Netherlands struggle to combine their subgroup with the host's national identity and that those who want to maintain strong links with their Turkish backgrounds tend to have a stronger propensity for disidentification with typical Dutch consumers. The current study complements this research stream.

Inspired by theories about attitudes (Arends-Tóth and van de Vijver, 2003; Fishbein, 1967), consumer acculturation (Askegaard, Arnould and Kjeldgaard, 2005; Laroche and Jamal, 2015) and domain-specific models of acculturation (Quarasse and van de Vijver, 2004), acculturation attitudes and acculturation behaviors are investigated in predicting consumption choices across the private- and public-life domains.

This paper is organized into four parts. First, the literature related to acculturation, attitudes toward host and heritage cultures and domain-specific models of acculturation is reviewed. Then the methodology is outlined and findings are reported. Finally, the theoretical, practical and policy implications of findings and present suggestions for future research is discussed.

\section{Literature Review}

\subsection{Acculturation}

Acculturation refers to the phenomena that result when different cultures meet and interact (Schwartz et al., 2010). Prior research (Berry, 1980, 1997; Gentry et al., 1995) identifies four modes of acculturation: integration, assimilation, separation, and marginalization. The assimilation defines the individual's preference for adopting the host culture's values and traditions over a period of time while gradually losing interest in maintaining his or her heritage culture. In contrast, the separation strategy finds an individual placing value on holding onto their heritage culture and avoiding interactions 
with the host culture. Integration occurs when there is an interest in maintaining one's heritage culture while having daily interactions with the host culture (Berry, 1997). Finally, marginalization occurs when the individual feels rejected by the host culture but also has no aspirations or desire to maintain the heritage culture.

Peñaloza's (1994) seminal work identifies conflicting sets of acculturation agents (e.g., family, friends, media, social and religious institutions), each aligned with the heritage and host cultures, that have effects on consumer acculturation outcomes. Subsequent work identifies entrenched subcultures (Wamwara-Mbugua, Cornwell and Boller, 2008) and global consumer culture (Askegaard et al., 2005) as additional acculturation agents. The underlying assumption is that immigrant consumers continuously negotiate and renegotiate identity projects based on their understanding of and willingness to adopt or reject the push (pull) effects associated with multiple acculturation agents.

\subsection{Bidimensional Acculturation}

Two acculturation models (unidimensional and bidimensional) explain how immigrant consumers learn new culture in attitudinal and behavioral terms (Segev, Ruvio, Shoham and Velan, 2014). The unidimensional model assumes that the immigrant adopts the host culture while decreasing or losing emphasis on aspects of the ethnic heritage culture (Arends-Tóth and van de Vijver, 2006). The adaptation to the host culture and the loss of the heritage culture are non-sequitur outcomes of immigration in which an individual maintains the home culture and simultaneously acquires the host culture (Chattaraman, Rudd and Lennon, 2009). Immigrants may consume both home- and hostculture-related offerings (Askegaard et al., 2005).

Acculturation measurements have largely moved from unidimensional to 
bidimensional models (Yagmur and van de Vijver, 2012). The bidimensional acculturation model considers adjustment to the home culture and the host culture as independent processes (Berry, 1997) in studying immigrant consumers' consumption patterns (e.g., Chattaraman et al., 2009; Cleveland et al., 2009).

\subsection{Public- and Private-Life Domains}

Arends-Tóth and van de Vijver (2006) argue that immigrants may "seek economic or work assimilation and linguistic integration, while maintaining separation in family and marriage" (p. 145). The private-life domain is a personal-value-related domain, whereas the public domain constitutes the functional areas of life (Arends-Tóth and van de Vijver, 2003; 2006). For example, matters that relate to marriage and socialization of children belong to the private-life domain, whereas behavioral tendencies like language use and social interactions belong to the public-life domain (Arends-Tóth and van de Vijver, 2008). An immigrant consumer may prefer to consume traditional cultural items (e.g., food, music, dress and celebrations) while at home but mainstream cultural items while in the public domain. In other words, an immigrant consumer may seek to maintain her heritage culture in the private domain (life within the family and personal spheres of life) but may seek to assimilate culturally when in a public domain like school and the workplace, where she has contact with the dominant group (Arends-Tóth and van de Vijver, 2006). Support comes from multiple self (Markus and Nurius, 1986) and situational ethnicity (Stayman and Deshpandé, 1989) literature that reports consumers acting differently in different situations and with different individuals.

\subsection{Acculturation Attitudes}

Per the attitude-toward-object model (Fishbein, 1967), an attitude is a function of the presence or absence and evaluation of beliefs and/or attributes (Schiffman and Kanuk, 
2007). For example, an immigrant consumer may believe that the host society values and rewards hard work, promotes justice, safety and equality for all, and is strict in enforcing mainstream policies about migration. The total configuration of these beliefs about this host society represents the cognitive component of the immigrant consumer's attitude toward the host society. The information-integration process combines only the salient beliefs about the host society to form an overall evaluation of the concept (in this case, the concept of the host society). Accordingly, acculturation attitudes reflect the importance and desirability of salient beliefs that involve host and/or heritage cultures.

An attitude is a learned predisposition to behave in a consistently favorable/unfavorable manner (Evans et al., 2009) and, as learned predispositions, attitudes have a motivational quality such that they propel (repel) consumers toward (against) a particular behavior (Schiffman and Kanuk, 2007).

Acculturation attitudes that involve personal beliefs, such as those related to marriage and rearing children, belong to the private-life domain, while acculturation behaviors that involve the broader social aspects of life, such as language use, socializing, eating out, seeking help and advice from others, following the news and taking part in public celebrations, relate to the public-life domain (Arends-Tóth and van de Vijver, 2003; 2006; 2008). Accordingly, acculturation attitudes are placed under the private domain and acculturation behaviors (labelled as enculturation of the heritage culture and acculturation of the host culture) under the public-life domain (Figure 1). Positive acculturation attitude is labelled as "Attitude Dutch Culture" and negative acculturation attitude as “Attitude Turkish Culture."

As per in-group and out-group categorization theory (Tajfel, 1981), an immigrant consumer's perceptions of self and his/her ethnic identity are often dependent on social comparisons that he/she makes with out-groups (the host society), resulting in a favorable 
assessment and evaluation of the in-group (the heritage cultural group). The presence of a positive affect toward the in-group, combined with the absence of positive feelings toward out-group often leads to bias and prejudices (Brewer and Brown, 1998; Tajfel, 1981). Accordingly, an immigrant consumer may develop a negative acculturation attitude and attach importance to having a partner from the heritage culture and rearing children in the heritage culture's traditions (Arends-Tóth and van de Vijver, 2008).

On the other hand, an immigrant consumer may value certain aspects of the host culture (e.g., Arends-Tóth and van de Vijver, 2008; Jamal, 2003), especially in pursuit of economic advantage and success in the host society. Accordingly, he/she may develop a positive acculturation attitude, attaching importance to having a partner from the host culture and rearing children in the host culture's traditions. Therefore, the first set of hypotheses state:

H1: Negative acculturation attitudes relate positively to a) enculturation of the heritage culture and b) consumption of the heritage culture's food and entertainment products.

H2: Positive acculturation attitudes relate positively to a) acculturation of the host culture and b) consumption of the mainstream culture's food and entertainment products.

\subsubsection{Effects of Heritage Culture Enculturation and Host Culture Acculturation}

Large ethnic-minority subcultures across the Western world (Jamal, 2003) facilitate enculturation, which reflects the social processes by which immigrant consumers learn, maintain and reinforce their own heritage's culture. Wamwara-Mbugua et al. (2008) report the effects of "entrenched subcultures," when immigrant consumers access haircare services, nightclub entertainment and church services. Jamal (2003; 2005) reports the extent to which ethnic commercial institutions, community networks and religious 
institutions take an active interest in the creation and reinforcement of an ethnic minority's consumer culture. Immigrant consumers are more prone to consuming ethnically consistent products (food, music and dress) when the consumption context is ethnically relevant (e.g., spending time with family) than when it is associated with the mainstream or another ethnic group (Jamal, 2003; Stayman and Deshpandé, 1989). Chattaraman et al. (2009) show that acculturation behavior relates to immigrants' participation in heritage- and host-related consumption. Segev et al. (2014) also examine the impact of acculturation behaviors on heritage and mainstream brands and stores. The findings concur with research on acculturation, revealing that immigrants' heritage and host culture orientations manifest in their consumption of heritage and host cultural practices (Laroche, Kim, Tomiuk and Belisle, 2005). Based on this discussion, the following hypotheses are proposed:

H3: Enculturation of the heritage culture a) positively impacts the consumption of the heritage culture's food and entertainment products and b) negatively impacts consumption of the mainstream culture's food and entertainment products.

H4: Acculturation of the host culture a) positively impacts consumption of the mainstream culture's food and entertainment products and b) negatively impacts consumption of the heritage culture's food and entertainment products.

The conceptual framework and subsequent hypothesized relationships presented so far suggest that enculturation and acculturation may act as mediating variables. Therefore, the next set of hypotheses:

H5: The effect of negative acculturation attitudes on the consumption of the heritage 
culture's food and entertainment products is mediated positively through enculturation of the heritage culture.

H6: The effect of positive acculturation attitudes on the consumption of the mainstream culture's food and entertainment products is mediated positively through acculturation of the host culture.

\section{Methodology}

\subsection{Sample and Data Collection}

The data used in this study comes from the largest non-Western ethnic group in the Netherlands, the Turkish using Markteffect's panel, which is based on a probability sample of individuals that includes a representative sample of immigrants and majoritygroup members who participate in surveys. To ensure that the respondents have a Turkish background, a screening question ("Do you have a Turkish background?") was sent by email. The 1,197 respondents who answered the screening question positively were asked to continue with the survey, and 530 of these respondents completed the self-administered questionnaire, for a response rate of 44.3 percent. Sixty percent of the respondents were male and 40 percent were female. The majority of the respondents $(56 \%)$ were born in the Netherlands $(n=297), 41 \%$ were born in Turkey $(n=218)$ and the remaining $3 \%$ from other European countries $(\mathrm{n}=15)$.

The respondents' ages ranged between 18 and 74 years. The sample is well spread in terms of age, occupation, education and location within the Netherlands. The elements in this study are representative of the target population, Turkish-Dutch.

\subsection{Measures}

Consistent with prior research, this study measures attitudinal and behavioral 
acculturation using separate subscales (Arends-Tóth and van de Vijver, 2006; 2007). Acculturation attitudes concerning issues related to the private-life domain (e.g., "It is important to have a partner/relationship with a person with a Turkish background" and "It is important to have a partner/relationship with a person with a Dutch background") were measured using a 7-point scale ranging from "strongly disagree" through "neutral" to "strongly agree." The items (from Arends-Tóth and van de Vijver, 2006) refer to acculturation attitudes involving the Turkish and Dutch cultures, so they are directly transferable to the context and setting of this research and its assessment of the privatelife domain. The two-dimensional scales (Dutch vs. Turkish) were further informed by the work of Hui et al. (1992) and Jun, Ball and Gentry (1993), which recognize the twodimensional nature of acculturation: the individual's self-identification with the host culture and the extent of adaptation to the host culture.

Acculturation of the host culture and enculturation of the heritage culture were measured using eighteen items that capture the public-life domain. The questions are based on Arends-Tóth and van de Vijver (2007) using the "two-statement method"; first one assesses the respondent's behavior in relation to the host culture (e.g., "How often do you spend social time with Dutch people?") and second one assesses the respondent's behavior of his/her own ethnic heritage (e.g., "How often do you spend social time with Turkish people?"), each containing a balanced 7-point Likert scale, ranging from "1=never" to " $7=$ =always."

Consumption of food and entertainment products from the heritage and mainstream cultures was measured using eight items adapted from $\mathrm{Xu}$, Shim, Lotz and Almeida (2004). Each item was scored on a 7-point Likert scale ranging from "1=never" to "7=always." 


\section{Data Analysis and Findings}

This study examines a set of variables derived from the literature. The new setting and application (translated into Dutch), as well as the sample, require exploratory factor analysis (EFA) to examine the instruments before proceeding with the confirmatory factor analysis (CFA) and structural equation modelling (SEM) to test theory and the hypotheses.

\subsection{Exploratory Factor Analysis}

EFA of six items that measure acculturation attitudes (private-life domain) identified a two-factor solution with Attitude Turkish Culture and Attitude Dutch Culture accounting for 72 percent of the total variance (eigenvalues of 2.7 and 2.2, respectively). The eighteen items used to measure Turkish enculturation and Dutch acculturation were subjected to EFA and an examination of the factor solution, the item loadings and the anti-image correlation matrix. Two items ("How often do you spend social time with Dutch people?" and "How often do you speak the Dutch language with parents and family members?") were deleted from further analysis because of cross-loading. Subsequent EFA identified a two-factor solution with Turkish enculturation and Dutch acculturation, each of which involves the public-life domain: social interactions and language use. The two-factor solution accounts for 63 percent of the total variance (eigenvalues of 5.9 and 4.2 , respectively).

The EFA of eight items that measured the consumption of food and entertainment products (food-related habits, music, movies and attendance at cultural performances) from the heritage culture and the host culture estimated a two-factor solution that accounts for 64 percent of the total variance (eigenvalues of 3.1 and 2.7, respectively). 


\subsection{Confirmatory Factor Analysis}

The second stage of data analysis involved the execution of CFA using Amos 22 to determine the factor structure. Two items were deleted, one item for Turkish enculturation ("How often do you participate in Turkish public celebrations?") and one item for the heritage culture's food and entertainment ("How often do you attend Turkish cultural performances (theater and concerts)"?), based on the modification indices' revealing misspecifications associated with the pairing of error terms (Hair, Black, Babin and Anderson, 2010). The deletion of the two items does not significantly change the construct as initially conceptualized nor does it compromise the study's theoretical underpinnings. The CFA shows that all of the remaining fifteen acculturation items, six attitude items and seven food and entertainment items load highly on their corresponding factors and provide strong empirical evidence of their validity.

All remaining constructs have high factor loadings that are greater than the recommended threshold of 0.5 (Hair et al., 2010; Kline, 2011) and suggest convergent validity (Kline, 2011). Further assessment of convergence validity using average variance extracted (AVE) shows that all constructs are above the 0.50 cut-off point (Hair et al., 2010), with the AVE estimates (Table 1) between 0.610 and 0.810 . The composite reliability scores for each construct exceed the 0.70 threshold point suggested by Field (2000). Using Fornell and Larcker's (1981) assessment of discriminant validity by comparing the AVE with the corresponding inter-construct squared correlation estimates reveals that the AVE for all constructs is greater than the squared correlation between the constructs, supporting of discriminant validity (Fornell and Larcker, 1981).

Based on the results provided by standardized factor loading, AVE and reliability score, there is satisfactory evidence of the measurement model's validity. The 
measurement model and the standardized loadings, along with CR (Critical Ratio) and AVE are presented in Table 1. The square-root values of AVE compared with the corresponding construct inter-correlations are shown in Table 2.

[Insert Table 1 about here.]

[Insert Table 2 about here.]

Chi-square values are affected by sample size, so incremental and absolute fit indices are used (Hu and Bentler, 1999; Schumacker and Lomax, 2004). The measurement model indicates an acceptable fit (parsimony fit $\mathrm{x}^{2} / \mathrm{df}=4.219$, comparative fit index $(\mathrm{CFI})=0.91$; incremental fit index $(\mathrm{IFI})=0.91$; root mean square error of approximation $(\mathrm{RMSEA})=$ 0.07; standardized root mean square residual $(\mathrm{SRMR})=0.06)$.

Following Podsakoff, MacKenzie, Lee and Podsakoff (2003), a common method bias test is conducted. Harman's single factor test is used to determine whether all variables can be accounted for by one latent factor, which would indicate that common method bias is not likely (total variance of $30.2 \%$ by a single factor). However, Podsakoff et al. (2003) claim that Harman's test may be incomplete and insensitive. Therefore, a common method factor assesses whether the measurement model is robust against common method variance. The results demonstrate that the average explained variance of the indicators is .70 , while the average method-based variance is .13, indicating a small method variance (a ratio of about 55:1). The results of the common method bias tests, with the evidence from the correlations, show that common method bias does not pose a serious threat to the measurement model and this study's results. 


\subsubsection{Measurement Model Equivalency}

A follow-up test examined whether country of birth is a boundary condition with regard to acculturation attitudes, acculturation/enculturation and consumption of food/entertainment (CFE). Two groups are constructed, one of respondents who were born in Turkey $(n=218)$ and the other of respondents who were born in the Netherlands $(n=297)$, excluding the group born in other European countries $(n=15)$. The mean scores and effect sizes are shown in Table 3.

[Insert Table 3 about here.]

To ensure measurement model invariance, multi-group CFA assesses model equivalence using a number of hierarchical steps in which the baseline model is compared against the other models (Steenkamp and Baumgartner, 1998). The test for equivalence requires validating the factorial structure of the measurement model for each group separatelythat is, whether the same CFA is valid for the group born in Turkey and the group born in the Netherlands-before simultaneously testing for invariance across the groups (Byrne, 2009).

The recommended Goodness-of-fit criteria for the invariance assessment are chisquare, CFI, RMSEA and SRMR (Hu and Bentler, 1999). However, research has suggested that invariance decisions should not be based on the chi-square values (Byrne and van de Vijver, 2010; Cheung and Rensvold, 2002) because chi-square is sensitive to sample size and a high number of parameters. The differences in CFI values are set as equal to or 0.01 and -0.01 as an indication of a substantial practical improvement for not rejecting invariance (Cheung and Rensvold, 2002). The estimation of the configural 
invariance model first show that the model fit statistics indicates an overall acceptable fit $\left(x^{2} / \mathrm{df}=3.072, \mathrm{CFI}=.886, \mathrm{RMSEA}=.064\right)$.

Modification Indices (MIs) are consulted to identify misspecifications that are due to nonequivalence of particular items across two groups (Byrne and van de Vijver, 2010; Steenkamp and Baumgartner, 1998) and found that the expected parameter change (EPC) statistics of four items' factor loadings and item scores fell outside the normal range. The MIs for Turkish language (EL5), Dutch language use (AL1), attitude Dutch culture (DC2) and mainstream CFE (MFE3) are .34, .29, .26 and .23, respectively. The EPC statistics indicate that the factor loadings of these items differ considerably between groups, so these four items were deleted because of model misspecification and lack of coherence (Byrne, 2009). Deletion of these items resulted in improvement in the configural invariance test. The deleted items showed differences between groups, but neither factor's content is altered by deleting the four items. These modifications result in an acceptable fit of the baseline model for the group born in Turkey $\left(x^{2} / \mathrm{df}=2.737, \mathrm{CFI}=\right.$ $.906, \mathrm{RMSEA}=.007)$ and the group born in the Netherlands $\left(x^{2} / \mathrm{df}=3.059, \mathrm{CFI}=.912\right.$, RMSEA = .007). The baseline measurement model 1 i.e. configural model across groups indicates a good fit; $x^{2} / \mathrm{df}=2.898, \mathrm{CFI}=.909, \mathrm{RMSEA}=.061, \mathrm{SRMR}=.061$ (presented in Table 4). All factor loadings are highly significant, and all standardized factor loadings exceed .61, allowing us to conclude the configural invariance of the hypothesized multigroup model with an acceptably good fit across the group that was born in Turkey and the group that was born in the Netherlands.

The next step involves metric invariance by increasing constraints on the invariant parameters. The metric invariance model (model 1a) in Table 4 shows that there is a significant decrease in chi-square between the configural model and full metric invariance model $\left(\Delta x^{2}(16)=26.89, \mathrm{p}<.05\right)$. Full metric invariance is usually not 
achieved, so the condition of partial measurement invariance should be reached (Steenkamp and Baumgartner, 1998). Byrne (1989) states that full metric invariance is not a pre-condition for further tests of invariance. The differences in the values of $\triangle$ RMSEA and $\triangle$ CFI between models 1 and 1a are within the threshold of 0.01 in measurement equivalence testing.

Finally, scalar invariance is tested, which refers to the constraints of measurement intercepts (Steenkamp and Baumgartner, 1998). The intercepts of the invariant factor loadings are constrained to be equal. Full scalar invariance for this model is not supported, as shown in model $1 \mathrm{~b}$ (Table 4). The increase in terms of chi-square is highly significant $\left(\Delta x^{2}(24)=89.70, \mathrm{p}<.001\right)$. The fit indices also show an overall decrease in model fit. Inspection of MIs indicates that the intercepts for Dutch language items (DL2 and DL4), heritage CFE (HFE1) and Turkish social interactions (ESI1) are not invariant across groups. Subsequently relaxing these four constraints yields a significant improvement in fit in model 1c (Table 4) in comparison to the full scalar invariance model (model 1b). Partial scalar invariance is supported by the insubstantial decrease in goodness-of-fit (GOF) indices in the partial scalar invariance test compared with the GOF indices in the configural model $\left(\Delta x^{2}(24)=31.85, \Delta \mathrm{CFI}=-.002, \Delta \mathrm{RMSEA}=-.001\right)$.

Additional conditions of invariance (i.e., covariance invariances and invariant factor variance) are tested. The covariance invariances in model $1 \mathrm{~d}$ are accepted $\left(\Delta x^{2}(7)\right.$ $=44.18, p<.001)$, as are the variant factor variances in model 1e after relaxing the factor constraint of Dutch social interactions (because of a difference in factor invariance between the two groups, as indicated by a high MI). The difference in the chi-square terms is significant $\left(\Delta x^{2}(2)=22.98, p<.001\right)$, while the fit indices CFI and SRMR increase and RMSEA remains the same. Covariance invariances and invariant factor variances (models $1 \mathrm{~d}$ and 1e) are also accepted. 
Considering the number of parameters, measurement equivalence of the model for each behavioral construct (i.e., heritage $C F E$ and host $C F E$ ) must be assessed separately. The models result in good, conventional cut-off levels (Hu and Bentler, 1999). The difference between the configural measurement model's $\Delta x^{2}$ and the metric invariance model's $\Delta x^{2}$ is significant $\left(\Delta x^{2}(16)=29.28, \mathrm{p}<.05 ; \Delta x^{2}(16)=44.50, \mathrm{p}<.05\right)$, while the fit indices CFI, RMSEA and SRMR are not significantly improved. Therefore, partial measurement invariance and model fit is accepted for two behavior categories: heritage $C F E$ and mainstream CFE.

The measurement invariance assessment criterion in this study are $x^{2}$, CFI, RMSEA, SRMR and the examination of the overall fit for the invariant model, while considering that chi-square is sensitive to sample size. The sequential testing of invariance indicates partial measurement invariance. In keeping with the measurement invariance literature (Cheung and Rensvold, 2002; Steenkamp and Baumgartner, 1998), stepwise measures of configural, metric, scalar, covariance and factor invariance is tested. The invariance test shows evidence for measurement invariance when four intercepts are freed to hold partial scalar invariance and the invariance constraint on Dutch social interactions is relaxed. Partial measurement invariance is accepted with less than 20 percent of freed parameters (Byrne, 1989). The factorial invariance (model 1e), which supports the meaning of the constructs, is the same in both groups (born in Turkey and born in the Netherlands). The conclusion of the invariance test is partial measurement invariance for the CFA measurement model across the two groups. The factor invariance test provides evidence of homogeneity in the factor scores (Steenkamp and Baumgartner, 1998) for the sample in this study.

[Insert Table 4 about here.] 


\subsection{Structural Equation Modelling}

After the measurement model was validated, structural equation analysis using Amos 22 assessed the relationships among the latent variables (Figure 1 and Table 6). Attitudes toward Turkish (Dutch) cultures relate to Turkish enculturation (Dutch acculturation) and consumption of the heritage (mainstream) CFE. Turkish enculturation (Dutch acculturation) relates to consumption of the heritage (mainstream) CFE. This analysis further confirms that the proposed factor structure is an appropriate representation of the underlying data. The GOF statistics show an acceptable fit, given the large sample size of 530 (Hair et al., 2010): $x^{2} / \mathrm{df}=4.320, \mathrm{CFI}=0.92$, IFI=0.92, RMSEA $=0.07$, SRMR $=0.07$. The structural model accounts for 68 percent of the variance in respondents' consumption of the heritage culture's products and 64 percent of the variance in consumption of the mainstream culture's products.

\subsection{Hypotheses}

Reviewing the structural parameter estimates (Table 5) shows that, except for H1b, H2b and $\mathrm{H} 4 \mathrm{~b}$, all remaining paths are significant. The analysis reveals a significant positive influence of Attitude toward Turkish culture on Turkish enculturation $(\beta=.73 p=.000)$ and a non-significant influence on consumption of the heritage $C F E(\beta=.09$, n.s.). Therefore, $\mathrm{H} 1 \mathrm{a}$ is accepted and $\mathrm{H} 1 \mathrm{~b}$ is rejected.

Attitude toward Dutch culture has a significant and positive influence on Dutch acculturation ( $\beta=.63 p=.000$ ) and a non-significant influence on consumption of the mainstream $C F E(\beta=.03$, n.s.). Therefore, $\mathrm{H} 2 \mathrm{a}$ finds support and $\mathrm{H} 2 \mathrm{~b}$ is rejected.

Turkish enculturation has a positive and significant influence on the consumption of the heritage $C F E(\beta=.75, p=.000)$ and is negatively associated with the mainstream 
$C F E(\beta=-.12, p=.000)$. These findings support $\mathrm{H} 3 \mathrm{a}$ and $\mathrm{H} 3 \mathrm{~b}$.

Dutch acculturation has a positive and significant influence on consumption of the mainstream $C F E(\beta=.771, p=.000)$ and a negative and non-significant influence on consumption of the heritage $C F E(\beta=-.03$, n.s. $)$. Findings provide support for $\mathrm{H} 4 \mathrm{a}$ but not for $\mathrm{H} 4 \mathrm{~b}$.

[Insert Table 5 about here.]

\subsection{Mediation Analysis}

The mediation analysis is conducted to determine whether enculturation and acculturation act as mediating variables. As Preacher and Hayes (2004) recommend, the bootstrapping methodology based on 5000 bootstrap resamples is used. The results, presented in Table 6, show that the effect of Attitude toward Turkish culture on consumption of the heritage $C F E$ becomes significant $(\beta=.55, p=.000)$, demonstrating that Turkish enculturation mediates the effect of Attitude toward Turkish Culture on the heritage CFE. The effect of Attitude toward Dutch culture on the consumption of the mainstream $C F E$ strengthens $(\beta=.48, p=.000)$ with the mediating effect of Dutch acculturation. According to Preacher and Hayes (2004), to test for the significance of the mediating effect, the bias-corrected and accelerated confidence intervals (CIs) must be evaluated. When Turkish enculturation and Dutch acculturation are examined as mediating factors, 95\% bias-corrected and accelerated bootstrap of CIs was obtained. Zero is not included within the $95 \%$ CIs in the lower and upper bounds of these CIs (Preacher and Hayes, 2004). The results indicate that Turkish enculturation has a significant indirect effect on the relationship between attitude toward Turkish culture and consumption of the heritage and mainstream CFE. Dutch acculturation shows a 
significant indirect effect in the relationship between attitude toward Dutch culture and consumption of the mainstream $C F E$, with an insignificant indirect effect in the relationship between attitude toward Dutch culture and consumption of the heritage CFE. In support of H5 and H6, Turkish enculturation and Dutch acculturation act as mediators in the relationships between negative (positive) acculturation attitudes and consumption of the heritage (mainstream) CFE.

[Insert Table 6 about here.]

\section{Discussion}

The study finds that acculturation attitudes especially those related to marriage and rearing children (private-life domain) play a significant role in predicting acculturation behaviors that involve broader social aspects of life, such as language use and social interactions. Findings are in line with those reported by others (e.g., ArendsTóth and van de Vijver, 2008). It appears that those who attach importance to having a partner from the heritage culture and rearing children in the heritage culture's traditions favor using their own ethnic language and mostly interact with people of their own culture. It could be that being Turkish resonates with being Muslim in Netherlands (Verkuyten and Yildiz, 2007) and a heightened sense of religious, cultural and ethnic identity (Jamal and Shukor, 2014; Sandikci and Ger, 2010) may underpin their preference for Turkish enculturation.

Similarly, those who attach importance to having a partner from the host culture and rearing children in the host culture's traditions favor using Dutch language and mostly interact with people of Dutch origin. It could be that such respondents' needs for education and employment and for regular interaction with mainstream media and friends 
fuel their desire to participate in the host culture (Maldonado and Tansuhaj, 2002) and hence a preference for Dutch acculturation. It could also be that such respondent value Dutch society's focus on rewarding hard work, promoting justice, safety and equality for all. Whatever the case, findings support previous research that reports immigrant consumers valuing certain aspects of the host culture (e.g., Arends-Tóth and van de Vijver, 2008 and Jamal, 2003), especially in pursuit of economic advantage and success in the host society.

Immigrant consumers, as this study's findings suggest, tend to be bicultural consumers in terms of acquiring the skills and knowledge that are relevant to their functioning in the host (Dutch) culture while maintaining strong identification with their heritage (Turkish) culture. Findings point to the complex and dynamic nature of living in a multi-cultural marketplace, where immigrants live with the need to maintain their culture at home but show solidarity with and become adjusted to the host culture.

Thus, immigrant consumers are influenced by both cultures (Askegaard et al., 2005), while coexist in a way in which culture is not traditionally defined. The findings suggest that marketers for both the heritage culture's and the host culture's products have potential consumers in the long-established and identifiable Turkish community that does not appear to be seeking separation in terms of its consumption choices.

The findings point to acculturation attitudes' being better predictors of acculturation behaviors than consumption choices are, perhaps because immigrant and host communities differ in their approaches to cultural maintenance and adaptation (Arends-Tóth and van de Vijver, 2003). Immigrant consumers face two fundamental issues: the first involves a decision about maintaining their culture of origin, and the second has to do with the extent to which they wish to have contact with and participate in the host culture (Berry, 1997). Such issues influence ethnic identity (Jamal and 
Chapman, 2000; Tajfel, 1981) and immigrant consumers construct personal and social identities on an ongoing basis based on their everyday conception of reality, which involves interactions within and outside immigrant groups (Jamal, 2003). The findings suggest that immigrants' acculturation attitudes involving their heritage and host cultures underpin the social construction of ethnic identity and, hence, have a significant impact on enculturation and acculturation.

This study finds that enculturation of the heritage culture positively impacts the consumption of the heritage culture's products (e.g., food, movies, music) and negatively impacts the consumption of the host culture's products. These findings support those reported by previous research (Grier et al., 2006; Peñaloza, 1994; Ratner and Kahn 2002) and strengthen the notion that entrenched ethnic subcultures (Jamal, 2003; WamwaraMbugua et al., 2008) facilitate the consumption of the heritage culture's products.

This study finds that acculturation of the host culture positively impacts consumption of the host culture's products and services. The results suggest that immigrant consumers who are in frequent contact with the host culture learn and take part in the host culture to a greater extent and are more receptive and influenced by the host culture than are those who have less contact with mainstream consumers. While such consumers become more acculturated (Kara and Kara, 1996), they still appear to have a strong association with their heritage culture (Jamal, 2003). Other findings suggest that immigrant consumers do not necessarily lose aspects of their heritage culture when they simultaneously adopt aspects of the host culture (Kim et al., 2001). 


\section{Managerial Implications}

Recent forecasts indicate that European populations will become more ethnically diverse and that the current majority indigenous population will soon be a minority in some countries (Eurostat, 2015). Furthermore, ethnic subgroups are younger on average than the rest of the Dutch population, so they are particularly attractive to marketers (CBS, 2014). The current model is relevant to Turkish-Dutch people in the Netherlands but has the potential to be adopted in similar immigration contexts.

The Turkish-Dutch segment is the largest non-Western immigrant group in the Netherlands, representing 10 percent of the population of immigrants in a total population of about 16 million (CBS, 2014). This study finds that those who favor their own cultures in their private lives also prefer to consume their own culture's food and entertainment products. Together with these findings, growth in the Turkish-Dutch population suggests strong entrepreneurial opportunities for businesses that want to target Turkish-Dutch consumers with culturally authentic products and services (Jamal, 2005). It is possible that the consumption preferences of Turkish-Dutch people in the Netherlands differ from those of others in Turkey, which provides opportunities for ethnic-product marketers to innovate and offer new products to meet the requirements of those in the Netherlands (e.g., Jamal, 2005). In addition, given the importance that Turkish-Dutch consumers attach to maintaining their culture at home, there are opportunities for businesses to improve how they reach and connect with these consumers by developing advertising messages that depict their cultural values (e.g., spending time with one's partner and children at home) and symbols (e.g., models of Turkish-Dutch lineage). This suggestion is in line with self-referencing theory (Lee, Fernandez and Martin, 2002; Meyers-Levy and Peracchio 1996), which argues that consumers are more likely to remember and like advertising messages that relate to the consumers' self-concepts. 
This research also finds that Turkish-Dutch consumers favor both their own culture and that of the host country in the public-life domain in terms of acculturation behaviors. The current political and policy debates on immigration in the Netherlands highlight the need for immigrant communities to integrate into the mainstream culture, and findings suggest that intercultural activities and programs that involve Turkish-Dutch people in the mainstream culture and media as both audience and producers can promote such integration. These findings also suggest that Turkish-Dutch consumers are willing to participate in public celebrations that provide opportunities for ethnic-product marketers to participate and introduce themselves to the wider community. This proposition is in line with the literature that reports that businesses develop stronger relationships with minority consumers by participating in public events that minority consumers enjoy (Jamal, 2005).

\section{Limitations and future research}

\subsection{Limitations}

This study has a number of limitations. The study took place in the Netherlands, so its findings may be relevant only to the Turkish-Dutch citizens in the Netherlands and may not be generalizable to other immigrant communities. Although the study focuses on young adults aged 18-24, students and young adults often live with their parents and depend on resources from family, which may also affect their decisions related to consumption and spending.

\subsection{Future Research}

This study highlights a number of potentially interesting future research projects. Findings related to the role of public/private life domains and acculturation attitudes in 
explaining acculturation behaviors and consumption choices may be equally applicable to other immigrant groups (e.g., Moroccans, Indonesians and Icelanders living in Netherlands), different product types (hedonic, value expressive but also utilitarian), consumption and usage situations (e.g., publicly consumed vs. privately consumed), different cultural orientations (e.g., collectivist vs. individualistic) and should, therefore, be explored in future research.

\section{References}

Arends-Tóth, J. V., \& van de Vijver, F. J. R. (2003). Multiculturalism and acculturation: Views of Dutch and Turkish-Dutch. European Journal of Social Psychology, 33, 249266.

Arends-Tóth, J. V., \& van de Vijver, F. J. R. (2004). Domains and dimensions in acculturation: Implicit theories of Turkish-Dutch. International Journal of Intercultural Relations, 28(1), 19-35.

Arends-Tóth, J. V., \& van de Vijver, F. J. R. (2006). Assessment of psychological acculturation: Choices in designing an instrument. The Cambridge handbook of acculturation psychology. D. L. Sam, \& J. W. Berry (Eds.) (pp. 142-160). Cambridge: Cambridge University Press.

Arends-Tóth, J. V., \& van de Vijver, F. J. R. (2006). Issues in conceptualization and assessment of acculturation. In M. H. Bornstein, \& L. R. Cote (Eds.), Acculturation and parent-child relationships: Measurement and development (pp. 33-62). Mahwah, NJ: Erlbaum.

Arends-Tóth, J. V., \& van de Vijver, F. J. R. (2007). Acculturation attitudes: A comparison of measurement methods. Journal of Applied Social Psychology, 37(7), 1462-1488.

Arends-Tóth, J. V., \& van de Vijver, F. J. R. (2008). Family relationships among immigrants and majority members in the Netherlands: The role of acculturation. Applied Psychology: An International Review, 57(3), 466-487.

Askegaard, S., Arnould, E. J., \& Kjeldgaard, D. (2005). Postassimilationist ethnic consumer research: Qualifications and extensions. Journal of Consumer Research, 32(1), 160-170.

Berry, J. W. (1980). Acculturation as varieties of adaptation. In A. M., Padilla (Ed.), Acculturation: Theory, models and some new findings (pp. 9-46). Westview Press, Boulder, CO. 
Berry, J. W., Kim, U., Power, S., Young, M., \& Bujaki, M. (1989). Acculturation attitudes in plural societies. Applied Psychology, 38(2), 185-206.

Berry, J. W. (1992). Acculturation and adaptation in a new society. International Migration, 30(1), 69-85.

Berry, J. W. (1997). Immigration, acculturation and adaptation. Applied Psychology: An International Review, 46, 5-68.

Berry, J. W. (2005). Acculturation: Living successfully in two cultures. International Journal of Intercultural Relations, 29, 697-712.

Berry, J. W., Kim, U., Power, S., Young, M., \& Bujaki, M. (1989). Acculturation attitudes in plural societies. Applied Psychology, 38, 185-206.

Brewer, M. B., \& Brown, R. J. (1998). Intergroup relations. In D. T. Gilbert, \& S. T. Fiske (Eds.), The handbook of social psychology, 4(2) (pp. 554-594). Boston, MA: McGraw Hill.

Byrne, B. M. (1989). A primer of LISREL: Basic applications and programming for confirmatory factor analytic models. New York: Springer-Verlag.

Byrne, B. M. (2009). Structural equation modeling with AMOS: Basic concepts, applications, and programming (2nd ed.). New York: Routledge/Taylor \& Francis.

Byrne, B. M., \& van de Vijver, F. J. R. (2010). Testing for measurement and structural equivalence in large-scale cross-cultural studies: Addressing the issue of nonequivalence. International Journal of Testing, 10(2), 107-132.

Centraal Bureau voor de Statistiek (2014). Permanent onderzoek bevolking. Den Haag/Heerlen: Centraal Bureau voor de Statistiek. Available at: www.cbs.nl. Accessed on $02 / 2016$.

Chattaraman, V., Rudd, N. A., \& Lennon, S. J. (2009). Identity salience and shifts in product preferences of Hispanic consumers: Cultural relevance of product attributes as a moderator. Journal of Business Research, 62(8), 826-833.

Cheung, G. W., \& Rensvold, R. B. (2002). Evaluating goodness-of-fit indexes for testing measurement invariance. Structural Equation Modeling, 9(2), 233-255.

Cleveland, M., Laroche, M., Pons, F., \& Kastoun, R. (2009). Acculturation and consumption: Textures of cultural adaptation. International Journal of Intercultural Relations, 33(3), 196-212.

Eurostat (2015). Migration and Migrant Population Statistics. Available at: http://ec.europa.eu/eurostat/statistics-explained/index.php/Migration-and-migrant population statistics.

Evans, M., Foxall, G., \& Jamal, A. (2009). Consumer behaviour. Chicester: John Wiley and Sons. 
Field, A. (2000). Discovering statistics using SPSS for windows. London, Thousand Oaks, New Delhi: Sage publications.

Fishbein, M. A. (1967). Attitude and the prediction of behavior. In M. Fishbein (Ed.), Readings in attitude theory and measurement (pp. 477-492). New York: Wiley.

Fornell, C., \& Larcker, D. F. (1981). Evaluating structural equation models with unobservable variables and measurement error. Journal of Marketing Research, 18(1), 39-50.

Gentry, J., Jun, S., \& Tansuhaj, P. (1995). Consumer acculturation processes and cultural conflict: How generalizable is a North American model for marketing globally. Journal of Business Research, 32, 129-139.

Gordon, M. (1964). Assimilation in American life. New York: Oxford University Press.

Grier, S. A., Brumbaugh, A. \& Thornton, C. (2006). Crossover dreams: consumer responses to ethnic-oriented products. Journal of Marketing, 70(2), 35-51.

Hair, J. F., Black, W. C., Babin, B. J., \& Anderson, R. E. (2010). Multivariate data analysis (7th ed.). Prentice Hall, Upper Saddle River, New Jersey.

Horenczyk, G. (1997). Immigrants' perceptions of host attitudes and their Reconstruction of cultural groups. Applied Psychology, 46(1), 34-38.

Hu, L., \& Bentler, P. M. (1999). Cutoff criteria for fit indexes in covariance structure analysis: Conventional criteria versus new alternatives. Structural Equation Modeling, 6, $1-55$.

Hui, M. K., Joy, A., Kim, C., \& Laroche, M. (1992). Acculturation as a determinant of consumer behavior: Conceptual and methodological issues, Proceedings AMA Winter Educator's Conference, San Antonio.

Jamal, A. (2003). Marketing in a multicultural world: the interplay between marketing, ethnicity and consumption. European Journal of Marketing, 37(11/12), 1599-620.

Jamal, A. (2005). Playing to win: An explorative study of marketing strategies of small ethnic retail entrepreneurs in the UK. Journal of Retailing and Consumer Services, 12(1), $1-13$.

Jamal, A., \& Chapman, M. (2000). Acculturation and inter-ethnic consumer perceptions: Can you feel what we feel? Journal of Marketing Management, 16, 365-391.

Jamal, A., \& Shukor, S. (2014). Antecedents and outcomes of interpersonal influences and the role of acculturation: The case of young British-Muslims. Journal of Business Research, 67(3), 237-245.

Jamal, A., Peñaloza, L., \& Laroche, M. (2015). Introduction to ethnic marketing, The Routledge Companion to Ethnic Marketing, Routledge. 
Jimenez, F. R., Hadjimarcou, J., Barua, M. E., \& Michie, D. A. (2013). A cross-national and cross-generational study of consumer acculturation to advertising appeals. International Marketing Review, 30(5), 418-439.

Josiassen, A. (2011). Consumer disidentification and its effects on domestic product purchases: An empirical investigation in the Netherlands. Journal of Marketing, 75(2), 124-140.

Jun, S., Ball, D.A., \& Gentry, J. W. (1993). Modes of consumer acculturation. In Advances in Consumer Research. L. McAlister \& M. L. Rothschild (Eds.). Provo. Association for Consumer Research, 20, 76-82.

Kara, A., \& Kara, N. R. (1996). Ethnicity and consumer choice: a study of Hispanic decision processes across different acculturation levels. Journal of Applied Business Research, 12(2), 22-34.

Kim, C., Laroche, M., \& Tomiuk, M. A. (2001). A measure of acculturation for Italian Canadians: Scale development and construct validation. International Journal of Intercultural Relations, 25, 607-637.

Kline, R. B. (2011). Principles and practice of structural equation modeling (3rd ed.). New York: The Guilford Press.

Laroche, M., Kim, C., Hui, M. K., \& Joy, A. (1996). An empirical study of multidimensional ethnic change: The case of the French-Canadians in Quebec. Journal of Cross-Cultural Psychology, 27(1), 114-131.

Laroche, M., Kim, C., Hui, M., \& Tomiuk, M. A. (1997). A multidimensional perspective on acculturation and its relative impact on consumption of convenience foods. Journal of International Consumer Marketing, 10(1/2), 33-56.

Laroche, M., Kim, C. \& Tomiuk, M. A. (1998). Italian ethnic identity and its relative impact on the consumption of convenience and traditional foods. Journal of Consumer Marketing, 15(2), 48-55.

Laroche, M., Kim, C., Tomiuk, M. A., \& Belisle, D. (2005). Similarities in Italian and Greek multidimensional ethnic identity: Some implications for food consumption. Canadian Journal of Administrative Sciences, 22(2), 143-167

Laroche, M., \& Jamal, A. (2015) Models of culture change, The Routledge Companion to Ethnic Marketing Routledge.

Lee, C. K. C., Fernandez, N., \& Martin, B. A. S. (2002). Using self-referencing to explain the effectiveness of ethnic minority models in advertising. International Journal of Advertising, 21(3), 367-379.

Markus, H., \& Nurius, P. (1986). Possible selves. American Psychologist, 41, 954-969. 
Meyers-Levy, J., \& Peracchio, L. A. (1996) Moderators of the impact of self-reference on persuasion. Journal of Consumer Research, 22(4), 408-423.

Peñaloza, L. (1994). Atravesando Fronteras/border crossings: A critical ethnographic exploration of the consumer acculturation of Mexican immigrants. Journal of Consumer Research, 289-294.

Podsakoff, P. M., MacKenzie, S. B., Lee, J. Y., \& Podsakoff, N. P. (2003). Common method biases in behavioral research: a critical review of the literature and recommended remedies. Journal of Applied Psychology, 88, 879-903.

Preacher, K. J., \& Hayes, A. F. (2004). SPSS and SAS procedures for estimating indirect effects in simple mediation models. Behavior Research Methods, Instruments, and Computers, 36, 717-731.

Quarasse, O., \& van de Vijver, F. J. R. (2004). Structure and function of the perceived acculturation context of young Moroccans in the Netherlands. International Journal of Psychology, 39(3), 90-204.

Ratner, R. K., \& Kahn, B. E. (2002). The impact of private versus public consumption on variety-seeking behavior. Journal of Consumer Research, 29(2), 246-257.

Sandikci, Ö., \& Ger, G. (2010). Veiling in style: How does a stigmatized practice become fashionable? Journal of Consumer Research, 37(1), 15-36.

Schiffman, L. G., \& Kanuk, L. L. (2007). Consumer Behavior (9th ed.). Pearson: Prentice Hall, New Jersey.

Schumacker, R. E., \& Lomax, R. G. (2004). A beginner's guide to structural equation modeling (2nd ed.). Lawrence Erlbaum Associates, Inc., Mahwah, NJ.

Schwartz, S. J., Unger, J. B., Zamboanga, B. L., \& Szapocznik, J. (2010). Rethinking the concept of acculturation: Implications for theory and research. American Psychologist, $65,237-251$.

Segev, S., Ruvio, A., Shoham, A., \& Velan, D. (2014) Acculturation and consumer loyalty among immigrants: a cross-national study. European Journal of Marketing, 48(9/10), 1579-1599.

Sheikh, N., \& Thomas, J. (1994). Factors influencing food choice among ethnic minority adolescents. Nutrition and Food Science, 4, 18-22.

Stayman, D. M., \& Deshpandé, R. (1989). Situational ethnicity and consumer behavior. Journal of Consumer Research, 16(3), 361-371.

Steenkamp, J. E. M., \& Baumgartner, H. (1998). Assessing measurement invariance in cross-national consumer research. Journal of Consumer Research, 25(1), 78-90.

Tajfel, H. (1981). Human groups and social categories: Studies in social psychology. Cambridge: Cambridge University Press. 
Verkuyten, M., \& Yildiz, A. (2007). National (dis)identification and ethnic and religious identity: A study among Turkish-Dutch Muslims. Personality and Social Psychology Bulletin, 33, 1448-1462.

Wallendorf, M., \& Reilly, M. D. (1983). Ethnic migration, assimilation, and consumption. Journal of Consumer Research, 10(3), 292-302.

Wamwara-Mbugua, L. W., Cornwell, T. B., \& Boller, G. (2008). Triple acculturation: The role of African Americans in the consumer acculturation of Kenyan immigrants. Journal of Business Research, 61(2), 83-90.

Xu, J., Shim, S., Lotz, S., \& Almeida, D. (2004). Ethnic identity, socialization factors, and culture-specific consumption behavior. Psychology \& Marketing, 2(21), 93-112.

Yagmur, K., \& van de Vijver, F. J. R. (2012). Acculturation and language orientations of Turkish immigrants in Australia, France, Germany, and the Netherlands. Journal of Cross-Cultural Psychology, 43(7), 1110-1130. 
Table 1: Item Loadings

\begin{tabular}{|c|c|c|}
\hline & $\begin{array}{l}\text { Standardized } \\
\text { Loadings }\end{array}$ & $\mathbf{C R}$ \\
\hline \multicolumn{3}{|l|}{$\begin{array}{l}\text { Heritage culture Enculturation } \\
(\alpha=.943, \text { Composite reliability }=0.884, \mathrm{AVE}=0.794)\end{array}$} \\
\hline $\begin{array}{l}\text { Public Domain Social Interactions } \\
(\alpha=.906, \text { Composite reliability }=0.909, \mathrm{AVE}=0.770)\end{array}$ & 0.824 & fixed \\
\hline ESI1-How often do you spend social time with Turkish people? & 0.834 & fixed \\
\hline ESI2-How often do you ask for help/advise of Turkish students/colleagues? & 0.862 & 24.555 \\
\hline ESI-3How often do you eat with Turkish friends/ colleagues? & 0.934 & 27.381 \\
\hline $\begin{array}{l}\text { Public Domain Language Use } \\
(\alpha=.941, \text { Composite reliability }=0.953, \mathrm{AVE}=0.803)\end{array}$ & 0.953 & 18.568 \\
\hline EL1-How often do you speak the Turkish language? & 0.935 & fixed \\
\hline EL2-How often do you speak the Turkish language with Turkish friends? & 0.918 & 38.237 \\
\hline EL3-How often do you speak the Turkish language with parents and family? & 0.834 & 29.234 \\
\hline $\begin{array}{l}\text { EL4-How often do you speak the Turkish language with children and young } \\
\text { family members? }\end{array}$ & 0.887 & 34.407 \\
\hline \multirow{2}{*}{\multicolumn{3}{|c|}{$\begin{array}{l}\text { Host culture Acculturation } \\
(\alpha=.887, \text { Composite reliability }=0.865, \mathrm{AVE}=0.774)\end{array}$}} \\
\hline & & \\
\hline $\begin{array}{l}\text { Public Domain Social Interactions } \\
(\alpha=.828, \text { Composite reliability }=0.836, \mathrm{AVE}=0.630)\end{array}$ & 1.076 & fixed \\
\hline ASI2-How often do you participate in Dutch public celebrations? & 0.781 & fixed \\
\hline ASI3-How often do you eat with Dutch friends/ colleagues? & 0.869 & 18.998 \\
\hline ASI4-How often do you ask help or advice of Dutch students/colleagues? & 0.725 & 17.218 \\
\hline $\begin{array}{l}\text { Public Domain Language Use } \\
(\alpha=.889, \text { Composite reliability }=0.892, \mathrm{AVE}=0.674)\end{array}$ & 0.624 & 11.294 \\
\hline AL1-How often do you speak the Dutch language? & 0.849 & fixed \\
\hline AL2-How often do you speak the Dutch language with Turkish friends? & 0.775 & 20.538 \\
\hline $\begin{array}{l}\text { AL4-How often do you speak the Dutch language with children and young } \\
\text { family members? }\end{array}$ & 0.850 & 23.411 \\
\hline AL5-How often do you follow the Dutch news? & 0.807 & 21.773 \\
\hline \multicolumn{3}{|l|}{$\begin{array}{l}\text { Attitudes Turkish } \\
(\alpha=.925, \text { Composite }\end{array}$} \\
\hline TC1-It is important to rear children in the Turkish culture & 0.913 & fixed \\
\hline $\begin{array}{l}\text { TC2-It is important to have a partner/relationship with a person with Turkish } \\
\text { background }\end{array}$ & 0.87 & 28.781 \\
\hline TC3-It is important to have the Turkish culture in my life & 0.916 & 29.185 \\
\hline \multicolumn{3}{|l|}{$\begin{array}{l}\text { Attitudes Dutch } \\
(\alpha=.820 \text {, Composite reliability }=0.824, \mathrm{AVE}=0.610)\end{array}$} \\
\hline DC1-It is important to rear children in the Dutch culture & 0.754 & fixed \\
\hline $\begin{array}{l}\text { DC2-It is important to have a partner/relationship with a person with Dutch } \\
\text { background }\end{array}$ & 0.744 & 17.266 \\
\hline DC3-It is important to have the Dutch culture in my life & 0.841 & 15.949 \\
\hline \multicolumn{3}{|l|}{$\begin{array}{l}\text { Heritage culture's food and entertainment } \\
(\alpha=.860 \text {, Composite reliability }=0.874, \mathrm{AVE}=0.698)\end{array}$} \\
\hline HFE1-How often do you eat Turkish meals/food? & 0.760 & fixed \\
\hline HFE3-How often do you watch Turkish movies? & 0.843 & 18.374 \\
\hline HFE4-How often do you listen to Turkish music? & 0.898 & 19.875 \\
\hline \multicolumn{3}{|l|}{$\begin{array}{l}\text { Mainstream culture's food and entertainment } \\
(\alpha=.865 \text {, Composite reliability }=0.863, \mathrm{AVE}=0.613)\end{array}$} \\
\hline MFE1-How often do you listen to Dutch music? & 0.862 & fixed \\
\hline MFE2-How often do you watch Dutch movies? & 0.793 & 17.342 \\
\hline $\begin{array}{l}\text { MFE3-How often do you attend Dutch cultural performances? (Theater and } \\
\text { concerts) }\end{array}$ & 0.791 & 15.728 \\
\hline MFE4-How often do you eat Dutch meals/food? & 0.675 & 16.663 \\
\hline
\end{tabular}


Table 2: Construct correlation

\begin{tabular}{|c|c|c|c|c|c|c|}
\hline & $\begin{array}{l}\text { Attitude } \\
\text { Turkish } \\
\text { culture }\end{array}$ & $\begin{array}{l}\text { Attitude } \\
\text { Dutch } \\
\text { culture }\end{array}$ & $\begin{array}{l}\text { Turkish } \\
\text { Encul- } \\
\text { turation }\end{array}$ & $\begin{array}{l}\text { Dutch } \\
\text { Accul- } \\
\text { turation }\end{array}$ & $\begin{array}{c}\text { Heritage } \\
\text { culture's } \\
\text { food and } \\
\text { entertainment }\end{array}$ & $\begin{array}{c}\text { Mainstream } \\
\text { culture's } \\
\text { food and } \\
\text { entertainment }\end{array}$ \\
\hline Attitudes Turkish culture & 0.900 & & & & & \\
\hline Attitudes Dutch culture & -0.099 & 0.781 & & & & \\
\hline Turkish Enculturation & 0.727 & -0.152 & 0.891 & & & \\
\hline Dutch Acculturation & -0.056 & 0.559 & 0.093 & 0.880 & & \\
\hline $\begin{array}{l}\text { Heritage culture's food and } \\
\text { entertainment }\end{array}$ & 0.651 & -0.141 & 0.833 & -0.004 & 0.836 & \\
\hline $\begin{array}{l}\text { Mainstream culture's food and } \\
\text { entertainment }\end{array}$ & -0.182 & 0.520 & -0.055 & 0.752 & -0.012 & 0.783 \\
\hline
\end{tabular}

Table 3: Mean differences between consumers born in Turkey and the Netherlands

\begin{tabular}{|c|c|c|c|c|c|}
\hline \multirow[b]{2}{*}{ Construct } & \multicolumn{2}{|c|}{$\begin{array}{l}\text { Born in } \\
\text { Turkey }\end{array}$} & \multicolumn{2}{|c|}{$\begin{array}{l}\text { Born in the } \\
\text { Netherlands }\end{array}$} & \multirow[t]{2}{*}{$\begin{array}{l}\text { Effect } \\
\text { Size } \\
\end{array}$} \\
\hline & $\mathbf{M}$ & SD & $\mathbf{M}$ & SD & \\
\hline Attitudes Turkish culture & 4.65 & 1.69 & 4.20 & 1.75 & .27, n.s. \\
\hline Attitudes Dutch culture & 3.86 & 1.65 & 3.84 & 1.51 & $.01, \mathrm{n} . \mathrm{s}$. \\
\hline Turkish Enculturation & 4.66 & 1.24 & 4.37 & 1.31 & .23 , n.s. \\
\hline Dutch Acculturation & 4.49 & 1.25 & 4.80 & 1.01 & .09 , n.s. \\
\hline Heritage culture's food and entertainment & 4.74 & 1.25 & 4.53 & 1.26 & .02 , n.s. \\
\hline Mainstream culture's food and entertainment & 4.09 & 1.27 & 4.08 & 1.50 & .00, n.s. \\
\hline
\end{tabular}

*** Significant at the $p<0.001 ; * *$ Significant at $p<0.01$; *Significant at $p<0.05$, Effect size is defined as the difference of the Turkish and Dutch mean score, divided by the standard deviation of the difference scores. Scores closer to zero refer to less preference of either culture.

Table 4: Multi-group model

\begin{tabular}{|c|c|c|c|c|c|c|}
\hline Model & $x^{2}(d f)$ & $x^{2} / d f$ & CFI & RMSEA & SRMR & $\Delta x^{2}(\Delta d f)$ \\
\hline 1. Configural Invariance & $1344.65^{* * * *}(464)$ & 2.898 & .909 & .061 & .060 & \\
\hline 1a. Metric invariance & $1371.54^{* * * *}(480)$ & 2.857 & .908 & .060 & .061 & $26.89^{*}(16)$ \\
\hline 1b. Full scalar invariance & $1461.24^{* * * *}(504)$ & 2.899 & .901 & .061 & .061 & $89.70^{* * * *}(24)$ \\
\hline 1c. Partial scalar invariance & $1376.50^{* * *}(490)$ & 2.852 & .907 & .060 & .061 & $84.74^{* *}(14)$ \\
\hline 1d. Factor covariances invariance & $1420.68^{* * * *}(497)$ & 2.859 & .905 & .060 & .079 & $44.18^{* * *}(7)$ \\
\hline 1e. Factor invariance & $1397.70^{* * * *}(488)$ & 2.864 & .906 & .060 & .068 & $22.98^{* * *}(9)$ \\
\hline \multicolumn{7}{|l|}{$\begin{array}{l}\text { Heritage culture's Food and } \\
\text { Entertainment }\end{array}$} \\
\hline 2. Configural invariance & $1125.97^{* * * *}(348)$ & 3.236 & .910 & .066 & .063 & \\
\hline 2a. Metric invariance & $1155.25^{* * *}(364)$ & 3.174 & .908 & .065 & .064 & $29.28^{* *}(16)$ \\
\hline \multicolumn{7}{|l|}{$\begin{array}{l}\text { Mainstream culture's Food and } \\
\text { Entertainment }\end{array}$} \\
\hline 3. Configural invariance & $1015.38^{* * *}(350)$ & 2.901 & .920 & .061 & .063 & \\
\hline 3a Metric invariance & $1059.88^{* * *}(366)$ & 2.896 & .917 & .061 & .064 & $44.5^{* * * *}(16)$ \\
\hline
\end{tabular}


Table 5: Structural Model Estimates

$\begin{array}{lllll}\text { Estimates } & \text { Std. } & \text { C.R. } & p & \text { St.Estimates }\end{array}$

Error

\begin{tabular}{|c|c|c|c|c|c|}
\hline H1a Attitudes Turkish culture $\rightarrow$ Turkish enculturation & .567 & .031 & 18.178 & .000 & .726 \\
\hline $\begin{array}{l}\text { H1b Attitudes Turkish culture } \rightarrow \text { Heritage culture's food } \\
\text { and entertainment }\end{array}$ & .060 & .034 & 1.774 & .076 & .098 \\
\hline H2a Attitudes Dutch culture $\rightarrow$ Dutch acculturation & .391 & .048 & 8.226 & .000 & .627 \\
\hline $\begin{array}{l}\text { H2b Attitudes Dutch culture } \rightarrow \text { Mainstream culture's } \\
\text { food and entertainment }\end{array}$ & .031 & .061 & .505 & .614 & .033 \\
\hline $\begin{array}{l}\text { H3a Turkish enculturation } \rightarrow \text { Heritage culture's food } \\
\text { and entertainment }\end{array}$ & .592 & .054 & 10.934 & .000 & .752 \\
\hline $\begin{array}{l}\text { H3b Turkish enculturation } \rightarrow \text { Mainstream culture's food } \\
\text { and entertainment }\end{array}$ & -.121 & .036 & -3.350 & .000 & -.121 \\
\hline $\begin{array}{l}\text { H4a Dutch acculturation } \rightarrow \text { Mainstream culture's food } \\
\text { and entertainment }\end{array}$ & 1.165 & .117 & 9.988 & .000 & .771 \\
\hline $\begin{array}{l}\text { H4b Dutch acculturation } \rightarrow \text { Heritage culture's food and } \\
\text { entertainment }\end{array}$ & -.040 & .038 & -1.050 & .294 & -.034 \\
\hline
\end{tabular}

Goodness-of-fit statistics of the model:

Chi square $=1032.490$

degrees of freedom ( $d f) .239, p=.000$

$x 2 / d f=4.320$

Comparative-Fit-Index $($ CFI $)=.919$

Incremental Fit Index $($ IFI $)=.919$

Root Mean Square Error of Approximation $($ RMSEA) $=0.07$

Standardized $R M R=0.07$

\section{Table 6: Mediation analysis}

\begin{tabular}{lccc}
\hline & & \multicolumn{2}{c}{ Confidence } \\
& $\beta$ & Upper & Lower \\
\hline Indirect paths & & & \\
Attitudes Turkish culture $\rightarrow$ Heritage culture's products (a) & $.546 * * *$ & .659 & .446 \\
Attitudes Turkish culture $\rightarrow$ Mainstream culture's products (b) & $-.088^{* *}$ & -.029 & -.145 \\
Attitudes Dutch culture $\rightarrow$ Mainstream culture's products (b) & $.484 * * *$ & .627 & .369 \\
Attitudes Dutch culture $\rightarrow$ Heritage culture's products (a) & -.021 , n.s. & .018 & -.060 \\
\hline
\end{tabular}

Notes: (a) mediator is Turkish Enculturation, (b) mediator is Dutch Acculturation

$* * *$ Significant at the $p<0.001$; ** Significant at $p<0.01$; *Significant at $p<0.05$ 
Figure 1: Structural Equation Model

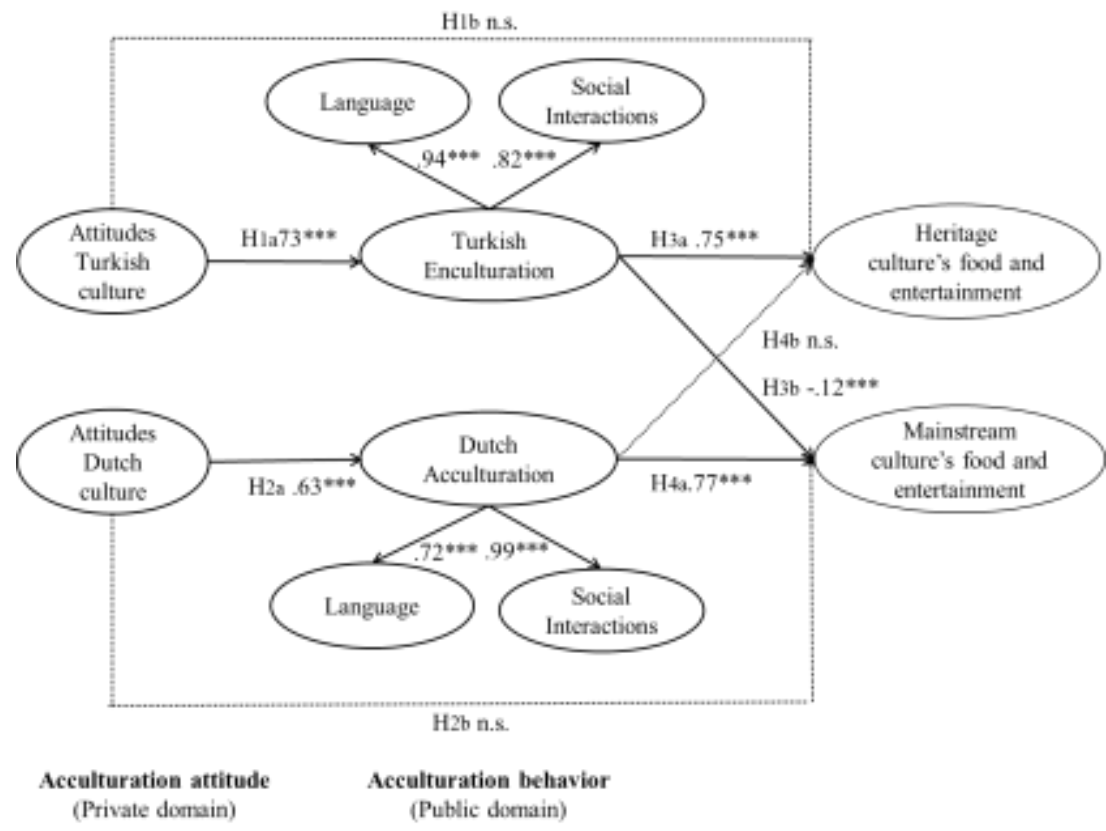

*** Significant at the $p<0.001 ; * *$ Significant at $p<0.01 ; *$ Significant at $p<0.05$ 